\title{
Empirical Analysis on Foreign Trade and Economic Development of Central China
}

\author{
Bo Song, Zhiji Li, Feng Zhou and Haiyang Yu \\ School of Education, Zhengzhou University, Zhengzhou 450001, China \\ songbodl@126.com, \{lizhiji2013, zhoufeng2013, yuhaiyang2013\}@126.com
}

\begin{abstract}
Based on the data of foreign trade and economic development of central China in 2001-2010, this paper explores the correlation between them. A linear regression analysis model to empirically explore the correlation between them is built. The result shows that there is a positive high linear correlation between foreign trade and economic development of central China. In central China, there is a long-term stability balance between foreign trade and economic development. They promote each other.

Index Terms - Foreign trade, Economic development, Empirical Analysis
\end{abstract}

\section{Introduction}

With the reform and opening of China, economic and social development has made a great achievement, especially in the east area. The development goals of the east coastal region have basically realized which makes a good example for other regions. In 2004, China put forward the development strategy of the rise of the central region, which includes Henan, Shanxi, Hebei, Anhui, Hunan and Jiangxi provinces. There is no doubt that foreign trade will be an important tool contributing to central China's rising.

In China, the central region is one of the most important grain production bases, and also one of the most important secondary industry bases. Nowadays, the east region has achieved advanced development in economy, and large-scale development plan of the western region is under the way. The central region, as a collapse region, must achieve its own development. There is no doubt that foreign trade is an important tool to realize economic development of the central China. Hence, this paper researches on the correlation between foreign trade and economic development of the central China, which is quite significant.

There are many published papers on foreign trade and economic development made by foreigners. For example, Balassa [1] studied the economic data from 11 countries using regression analysis. He explored the correlation between GDP growth and export growth, and also obtained a conclusion which is in favour of ELG hypothesis. Dollar [2] studied the 92 countries' economic date from 1976 to 1985, which arrived at the same conclusion with Balassa. Liu, song and Romilly [3] explored the correlation between GDP and export of China. Since the 1990s, some Chinese scholars began to explore the correlation between foreign trade and economic development of China, and obtained some results. He-lian $\mathrm{Xu}$ and Mingyong Lai [4] insisted that import trade made a great contribution to economic development of China. Shu-jie Yao and Kai-lei Wei [5] explored the interaction between export trade, foreign investment and economic development, and then concluded that both export and foreign investment have a positive effect on economic development. Bo Peng [6] estimated the short-term and long-term effects of foreign trade on economic development in western China. Hence, all the researches above support the conclusion that foreign trade could improve economic development no matter at home or abroad.

However, the correlation between foreign trade and economic development of central China is seldom researched. In this paper, we explore the correlation between foreign trade and economic development of central China, based on the data of foreign trade and economic development of central China in 2001-2010.

The rest of the paper is organized as follows. In section 2, the correlation analysis between foreign trade and economic development of central China is resented. In section 3, we empirically explore the correlation between them. Concluding remarks are given in section 4.

\section{The Correlation Analysis between Foreign Trade and Economic development of Central China}

\section{A. foreign Trade and Economic Development of Central China}

With the reform and opening of China, the economy of China rises at a high speed. Over the past several years, China has enjoyed one of the world's fastest growing economies and has been a major contributor to world economic growth. In 2010, Chinese GDP reached 39798.3 billion Yuan, increased $10.3 \%$, compared with the last year. At the same time, China makes great efforts to promote foreign trade between other countries. In 2010, the total value of imports and exports of China had been arrived at 116.89 billion dollars, increased $50.05 \%$, compared with last year. All data are from the 2010 China Statistical Yearbook.

In the following section, we will explore the data of foreign trade and economic development of central China, which are showed in TABLE I as follows. 
TABLE I The data of foreign trade and economic development of central China in 2001-2010

\begin{tabular}{|c|c|c|}
\hline Year & $\begin{array}{c}\text { GDP } \\
(100 \text { millions Yuan })\end{array}$ & $\begin{array}{c}\text { Foreign Trade } \\
(100 \text { millions dollars })\end{array}$ \\
\hline 2001 & 20697.36 & 248.34 \\
\hline 2002 & 22694.84 & 287.05 \\
\hline 2003 & 25870.88 & 314.27 \\
\hline 2004 & 31616.34 & 352.52 \\
\hline 2005 & 37411.17 & 415.1 \\
\hline 2006 & 43480.57 & 539.8 \\
\hline 2007 & 52971.08 & 743 \\
\hline 2008 & 64040.56 & 989.3 \\
\hline 2009 & 70577.56 & 779 \\
\hline 2010 & 86013.45 & 1168.9 \\
\hline
\end{tabular}

Data sources: the China Statistical Yearbook and China Business Yearbook from 2001 to 2010.

For the sake of convenience, we made two figures (i.e., Fig. 1 and Fig. 2) to show the rising tendency of foreign trade and GDP of central China.

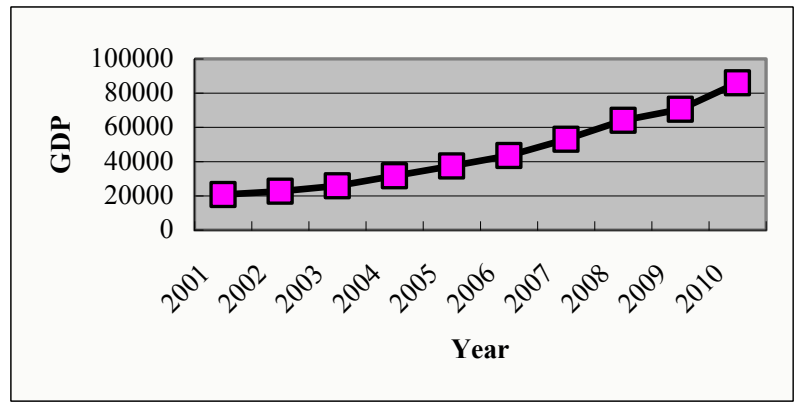

Fig. 1. The rising tendency of GDP of central China

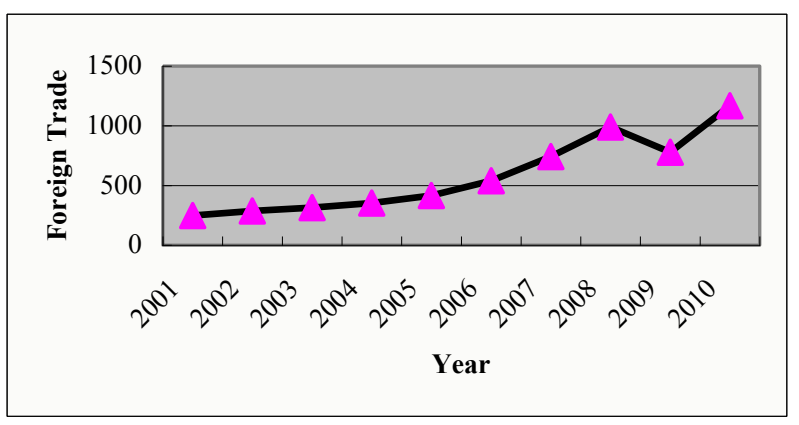

Fig. 2. The rising tendency of foreign trade of central China

According to these two figures, we know since from 2001 to 2008, both foreign trade and GDP of central China are growing steadily. China has been a member of WTO since 11 December 2001. Since then, both foreign trade and GDP of central China have maintained rapid development. In 2008, the international financial crisis spread from the developed countries to emerging economies and spilled over from the financial sector to the real economy. Since Chinese economy is heavily dependent on foreign trade and investment flows, the foreign trade and GDP of central China have slowed sharply in 2009. In 2009, China has taken a number of steps to respond to the global financial crisis. In addition to cutting interest rates and boosting bank lending, China has implemented a number of policies to stimulate and rebalance the economy, increase consumer spending, restructure and subsidize certain industries, and boost incomes for farmers and rural poor. Under these steps, both foreign trade and GDP of central China have arrived at rapid development again.

\section{B. Correlation Analysis between Foreign Trade and Economic Development of Central China}

The related data can explain the positive correlation between two variables, rather than exactly tell the degree of positive correlation. Karl Pearson, a famous statistician, designed the statistical index-correlation coefficient, which is used to reflect the correlation degree between two variables.

We usually denote $r$ the correlation coefficient. Its basic formula is as follows.

$$
r=\frac{\sum_{i=1}^{n}\left(x_{i}-\bar{x}\right)\left(y_{i}-\bar{y}\right)}{\sqrt{\sum_{i=1}^{n}\left(x_{i}-\bar{x}\right) \sum_{i=1}^{n}\left(y_{i}-\bar{y}\right)}}
$$

The value of the correlation coefficient is between -1 and 1, i.e., $-1 \leq r \leq 1$. Generally, when $|r|<0.4$ holds, it means a low linear correlation, a medium linear correlation when $0.4 \leq|r|<0.7$ holds, and a high linear correlation when $0.7 \leq|r|<1$ holds.

Denote ZTR the total value of exports and imports of central China, and ZGDP the GDP of central China. Here, we use the SPSS statistical analysis software to explore the data of TABLE I, and then obtain the correlation coefficient between foreign trade and economic development of central China. The result is shown in TABLE II.

TABLE II The correlation coefficient between foreign trade and economic development

\begin{tabular}{|c|l|l|l|}
\hline \multicolumn{2}{|l|}{} & ZGDP & ZTR \\
\hline ZGDP & Pearson Correlation & 1 & 0.970 \\
\hline ZTR & Pearson Correlation & 0.970 & 1 \\
\hline
\end{tabular}

According to TABLE II, the correlation coefficient between foreign trade and economic development of central China is 0.970 . The result shows that there is a high linear correlation between foreign trade and economic development of central China. It means that foreign trade is quite important to promote economic development of central China. According to statistics, if there is a high linear correlation between two variables, we can make a linear regression analysis based on the date. This will be specially explained in the following section. 


\section{Foreign Trade Dependence Degree, Foreign Trade Contribution Degree and Foreign Trade Pull Degree}

As be showed above, there a high linear correlation between foreign trade and economic development of central China. To research the correlation between them deeply, we need use three indexes described as follows.

Foreign Trade Dependence Degree (Denoted as $Y C D$ ) generally refers to the ratio of total foreign trade to GDP during a given period (usually one year). It is used to measure the opening degree of economy in a country or region, and it can reflect the dependence degree of economic development on foreign trade. Its computation formula is as follows.

$$
Y C D_{t}=\frac{Z T R_{t}}{Z G D P_{t}} \cdot 100 \%
$$

Foreign Trade Contribution Rate (Denoted as GXL) is the ratio of the incremental total foreign trade to incremental GDP. Its computation formula is as follows.

$$
G X L_{t}=\frac{\Delta Z T R_{t}}{\Delta Z G D P_{t}} \cdot 100 \%
$$

Foreign Trade Pull Degree (Denoted as $L D D$ ) is the product of GXL and GDP growth rate. Its computation formula is as follows.

$$
L D D_{t}=\frac{\Delta Z G D P_{t}}{Z G D P_{t-1}} \cdot G X L_{t} \cdot 100 \%=\frac{\Delta Z T R_{t}}{Z G D P_{t-1}} \cdot 100 \%
$$

TABLE III Three indexes of central China in recently nine years

\begin{tabular}{|c|c|c|c|c|c|c|}
\hline Year & Exchange Rate of Renminbi to USD & GDP growth rate & Foreign Growth Rate & $Y C D_{t}$ & $G X L_{t}$ & $L D D_{t}$ \\
\hline 2001 & 8.277 & --- & --- & $9.9313 \%$ & --- & --- \\
\hline 2002 & 8.277 & $9.6509 \%$ & $15.5875 \%$ & $10.4690 \%$ & $16.0403 \%$ & $129.0177 \%$ \\
\hline 2003 & 8.277 & $13.9945 \%$ & $9.4827 \%$ & $10.0546 \%$ & $7.0937 \%$ & $78.4880 \%$ \\
\hline 2004 & 8.2768 & $22.2082 \%$ & $12.1711 \%$ & $9.2286 \%$ & $5.5102 \%$ & $100.7375 \%$ \\
\hline 2005 & 8.1917 & $18.3286 \%$ & $17.7522 \%$ & $9.0892 \%$ & $8.8464 \%$ & $145.4206 \%$ \\
\hline 2006 & 7.9718 & $16.2235 \%$ & $30.0410 \%$ & $9.8968 \%$ & $16.3786 \%$ & $239.4805 \%$ \\
\hline 2007 & 7.604 & $21.8270 \%$ & $37.6436 \%$ & $10.6658 \%$ & $16.2808 \%$ & $286.2417 \%$ \\
\hline 2008 & 6.9451 & $20.8972 \%$ & $33.1494 \%$ & $10.7288 \%$ & $15.4531 \%$ & $230.2259 \%$ \\
\hline 2009 & 6.831 & $10.2076 \%$ & $-21.2575 \%$ & $7.5397 \%$ & $-21.9758 \%$ & $-145.2097 \%$ \\
\hline 2010 & 6.7695 & $21.8708 \%$ & $50.0513 \%$ & $9.1996 \%$ & $17.0993 \%$ & $338.8226 \%$ \\
\hline
\end{tabular}

According to TABLE III, foreign trade dependence degree always maintains about $10 \%$. This makes central China more international and influenced by world business. Since the connection of central China's economy and foreign economy is becoming much closer, the scale of foreign trade is growing fast, and then the foreign trade dependence degree of central China is also growing quickly. In 2004, the foreign trade dependence degree of the east region is $95.58 \%$, the average degree of China is $69.96 \%$ in that period. Hence, the level of $10 \%$ is still low, and we need improve the foreign trade dependence degree of central China greatly. As for the foreign trade structure, the main exports of central China are primary goods and the main imports are manufactured goods. The level of foreign trade of central China is still low. In a word, the economic opening degree of central China need be improved.

According to the analysis above, we may easily obtain the results as follows. Firstly, the foreign trade dependence degree of central China is growing year by year, but amplitude is relatively slow and the whole level is still low. Secondary, the foreign trade contribution rate of central China is increasing, but amplitude is relatively slow. Thirdly, the foreign trade pull degree had achieved steady growth. However, the pulling power is not enough. Thus, foreign trade promotes economic development of central China. Economic development in central China can not work without foreign trade.

\section{The Empirical Analysis between Foreign Trade and Central Economic Development}

In order to make quantitative analysis on the influence of foreign trade towards central China's economic development, we establish a linear regression analysis model to explore the correlation between foreign trade and economic development. We will make an empirical analysis on the correlation using this model.

According to the results above, we know that the correlation coefficient between foreign trade and economic development of central China is 0.970, which is quite high. According to the theory of Statistics, we can make curve fitting with Least Square Method, which enables us to make quantitative analysis on the influence of foreign trade towards central China's economic development. Taking ZGDP as the dependent variable, and ZTR as the independent variable, we can make a linear regression analysis using SPSS software. The result is shown in TABLE IV. 
TABLE IV The result of linear regression analysis

\begin{tabular}{|c|c|c|c|c|c|}
\hline $\begin{array}{c}\text { Dependent } \\
\text { variable }\end{array}$ & $\begin{array}{c}\text { Independent } \\
\text { variable }\end{array}$ & $\begin{array}{c}\text { Constant } \\
\text { coefficient }\end{array}$ & $\begin{array}{c}\text { Variable } \\
\text { coefficient }\end{array}$ & $R^{2}$ & $\mathrm{~F}$ \\
\hline ZGDP & ZTR & 6290.518 & 67.235 & 0.941 & 128.741 \\
\hline
\end{tabular}

Where $R^{2}$ shows the effect of the linear regression analysis, the more $R^{2}$ is close to 1 , the better linear regression fits. According to TABLE IV, we know that $R^{2}$ of our linear regression analysis is 0.941 , which shows the correlation between the ZGDP and ZTR is positive and high. The regression equation is described as follows.

$$
\begin{array}{lr}
Z G D P= & 67.235 Z T R+6290.518 \\
t: \quad(11.346) \quad(1.612)
\end{array}
$$

Where $t$ denotes the $t$-test value of the regression equation. According to the regression equation, the coefficient of ZTR passes the T-test and F-test, which means that our regression equation is made quite well. The result shows that there is a positive high linear correlation between foreign trade and economic development of central China.

\section{Conclusions}

Based on the data of foreign trade and economic development of central China in 2001-2010, this paper explores the correlation between them. And then, the paper establishes a linear regression analysis model to empirically explore the correlation between them. The result shows that there is a positive high linear correlation between foreign trade and economic development of central China.

In central China, there is a long-term stability balance between foreign trade and economic development. They promote each other. Without question, foreign trade is an important tool contributing to central China's rising. Consequently, for a long time, central China should insist on export-led stratagem.

\section{Acknowledgement}

The authors would like to thank Prof. Qian Zhou for his helpful comments to improve the work.

\section{References}

[1] B. Balassa, "Exports and Economic development: Further Evidence," Journal of Development Economics, vol. 5, no. 2, pp. 181-189, June 1978.

[2] D. Dollar, "Outward-oriented developing economics really do grow more rapidly: evidence of from 95LDCs, 1976-1985," Economic Development and Cultural Change, vol. 40, no. 3, pp. 523-544, April 1992.

[3] X. Liu, H. Song, and P. Romilly, "An empirical investigation of the casual Correlation between openness and economic development in China," Applied Economics, vol. 29, no. 12, pp. 1679-1686, December 1997.

[4] H. Xu and M. Lai, "An Empirical Analysis of Impact Factors of Imports in China," Journal of Hunan University (Social Sciences), vol. 16, no. 5, pp. 37-40, May 2002.

[5] S. Yao and K. Wei, "On Economic development, FDI and Exports in China," Applied Economics, vol. 38, no. 3, pp. 339-351, August 2006.

[6] B. Peng, "On the Correlation of Western areas foreign trade and Economic development," Thesis for master degree of Chongqing University, 2007. 